\title{
Pedagogies for critical agency: Portals to alternative futures
}

\author{
Rieta Ganas ${ }^{1 \#}$, Kasturi Behari-Leak ${ }^{2}$, Nalini Chitanand ${ }^{3}$, and Siya Sabata ${ }^{4}$ \\ ${ }^{1}$ University of the Witwatersrand \\ ${ }^{2}$ University of Cape Town \\ ${ }^{3}$ Durban University of Technology \\ ${ }^{4}$ Cape Peninsula University of Technology \\ "Corresponding Author: rieta.ganas@wits.ac,za
}

(Submitted: 4 October 2020; Accepted: 9 September 2021)

\begin{abstract}
'Pedagogies in context' are explored through a national project working with academic staff developers and new academics' induction and transitioning into higher education. Causallayered analysis is used to explore the interplay between academic staff, institutional development, and contextual influences in shaping professional learning processes. Data generated by the project's steering committee (SC) reflects on pedagogical encounters with the NATHEP participants and conference delegates (HELTASA, 2019). The outcomes of each intervention were compared by reflecting on who was in the room and how epistemological and ontological depth in each engagement was achieved. The study was guided by whether pedagogies are mobile and agile, irrespective of context. The SC asserts that pedagogies in context are relative to the participants, purpose and the project embedded in a specific context to achieve the epistemological, ontological, methodological, and axiological breadth and depth required. The portability of pedagogies from one context to another depends on aspects intrinsic to knowledge generation, transformation and decolonisation, engagement, being and becoming, and socio-cultural and historical conditions. This is also incumbent on the agility and flexibility of facilitators to adapt their repertoire to draw on a suite of contextually relevant pedagogical approaches.
\end{abstract}

Keywords: being and becoming, decoloniality, engagement, knowledge generation, portability, transformation,

\section{Introduction}

The Higher Education (HE) context in which academics and academic developers find themselves, undergoes continuous change, requiring us to disrupt our subjectivities and taken-for-granted assumptions to re-imagine our practices as academics. Interrogating our preconceived ideas and biases about the nature of learning and teaching forms an integral part of a required reflexive 
process. The traditional lecture method for example has often been considered the most appropriate pedagogy for $\mathrm{HE}$ spaces but contextually relevant pedagogies need to be considered too as this is inextricably linked to who we are as practitioners and how comfortable we are with our own sense of being. The diversity of HEls calls on us to step out and step up to problematising and theorising pedagogies in relation to context and its possible opportunities.

As steering committee members (SC) on a national collaborative project and as authors here, we draw on the work of the New Academics Transitioning into Higher Education Project (NATHEP) to re-imagine the role of Academic Development (AD) in South African (SA) Higher Education in achieving its transformative potential. We have focused on pedagogies for critical agency, to explore the ways in which AD pedagogies enable or constrain transformation. Using a self-reflexive method, we individually reflected as the SC members responsible for the NATHEP curriculum and its four selected pedagogical approaches. We then collectively confronted, interrogated, and uncovered biases, assumptions, and pre-conceptions about the project's selection, using Causal Layered Analysis (CLA) as a systematic frame to layer the project's pedagogical encounters and to work with the messages, meanings, and questions it raises (Inayatullah, 2004). By foregrounding the contextualisation of pedagogies, we became 'unstuck' ourselves. Our analysis and discussion show how we responded to the research question: Are pedagogies equally portable and agile irrespective of different contexts?

We used the metaphor of the "portal" that emerged from the SC engagement with pedagogies in context, to represent an opening and a door to our imagined future. It connotes the idea of portability or of being transported to different contexts. What emerges across the four pedagogical approaches is related to whether pedagogies are agile and portable, irrespective of the context.

The overarching theme of 'context' is a critical aspect used by NATHEP in their specific work on induction programmes to address the historical and systemic legacy challenges, especially in SA. Institutional differentiation is a considerable challenge as resources are unevenly distributed across the sector, affecting the quality of induction events at each university. Throughout the project the SC focused on how contextual enablements and constraints influence approaches to induction and what the induction programmes in different institutions are able to achieve.

To understand context, pedagogy became an important focal point of NATHEP as an explicit theoretical thrust during workshop facilitation, using a collaborative, consultative and inclusive methodology. The SC facilitated two workshops focused on pedagogies, one with NATHEP participants and one with the HELTASA 2019 conference delegates. Both workshops addressed the who (university teachers) and the how (pedagogies) but also the why (purpose), all of which play a critical role in mediating social practices. A variety of theorised, relevant, and contextualised pedagogies were modelled by the SC during workshops. This invited project and conference participants to extend their repertoire of existing practices by enabling them to engage first-hand with different approaches such as decolonisation and transformation pedagogies to effect change in their contexts, where structural and cultural morpho-stasis stifles innovation and change. 


\section{Background to the study The NATHEP Project}

This paper draws on the work of NATHEP, a national collaborative project funded by the University Capacity Development Grant (UCDG). NATHEP brings together Academic Staff Developers to theorise and conceptualise their institutional programmes on inducting new academics in relation to their different institutional types, contexts, and cohorts as well as their roles as university teachers. NATHEP is led by a project leader who is also part of a steering committee (SC) of five members; all of whom have extensive experience in conceptualising and offering induction programmes at their institutions. The $\mathrm{SC}$ is responsible for the implementation of the project plan, programme development and facilitation as well as serving as mentors to university participants. The project participants comprise twenty academic staff developers representing ten national universities identified by the project funder, DHET. The SC and participants attend national workshops organised by NATHEP and work in a community of practice to create, develop and enhance their customised induction programmes for their universities. The participants are supported to interrogate and address historical and systemic challenges that shape institutional professional learning spaces and to critically influence a cadre of new academics who can respond to the pressing challenges of our time. Based on a cascading model of staff development where the student is valued as the ultimate beneficiary of academic staff development (ASD), NATHEP prepares academic staff developers to engage in relevant and generative ways with their new academics. Through its curriculum and methodology, NATHEP foregrounds inclusive and participatory teaching and learning experiences that are responsive to institutional, regional, and national contexts. This is what we refer to here as "pedagogies-incontext".

\section{Theoretical Framing of NATHEP}

The meta-theoretical framing guiding both NATHEP's methodology, pedagogy and research outputs draws on critical realism (Bhaskar, 1990) and social realism (Archer, 2000). This informs the theoretical basis and methodology for the workshops as well as related research outputs such as this paper. Using Bhaskar's seven scalar being (2010) to unpack context, both temporally and spatially, NATHEP explored a spectrum of contextual influences, from the self to cosmology, to unpack how these influence how academic staff developers conceive of their roles in induction programmes and how new academics understand their roles as they transition into HE.

An organising framework derived from Bhaskar's Seven Levels (laminar) of Scale or Seven Scalar Being (2010) was used to guide the choice of methodology for this study. The laminated system refers to ontologically different levels, layers or contexts which are inseparable and irreducible when exploring social and natural phenomena. These include psychological, biographical, micro-level, meso-level, macro-level, mega-level, and the planetary or cosmological level. 
Critical realism advances the aspect of "emergence" which was observed in NATHEP when participants reflected on the pedagogic relationship, i.e. when teacher and student come together, 'outcomes' cannot be predicted, since contextual powers and properties are activated and triggered differently and influence what people do in different or similar situations. Social realism is used to explain the importance of critical agency which is crucial to how academic staff developers work with new academics who in turn work with students to mediate their structural and cultural conditions to bring about change.

\section{Methodology}

Influenced by critical realism's stratified reality (Bhaskar, 1990), we used Inayatullah's CLA (2004) (discussed below) (see Table 1) as both a methodological framing and analytical approach for this qualitative study. CLA is a systematised way of categorising or layering different events, views and concerns that often raises hidden meanings, ideologies, structures, and consciousness (Inayatullah, 2004). CLA consists of four levels of layering, namely Litany, Social, Worldview and Metaphor which has been re-contextualised to suit this study's events. The SC has drawn on these four levels as a heuristic and representational device for the methodological, theoretical, and conceptual frameworks and analysis for this study. As the authors, the SC was inspired to frame this paper in accordance with each CLA level which enabled us as individuals and a collective to work horizontally, vertically, and iteratively with the layers as a means to generate data.

Using CLA as a methodological approach, the SC used the CLA framework to generate data which reflected on "what was, what is and what is missing" in relation to contextualised pedagogical approaches that encourage critical learning and transformation. Through this approach, the SC engaged with their own transformative potential, by opening up the past and the present to envision the creation of alternative futures (Inayatullah, 2004) for pedagogies in HE. Deep reflections and thinking with and through the inclusion of different ways of knowing was a strong characteristic of the process. The layered approach constructed the problem through context at multiple levels (Inayatullah, 2004). Through deeper probing more critical possibilities were revealed which offered transformative potential for alternative futures (Inayatullah, 2004; Haigh, 2016). Data was generated at the different CLA levels to reflect on "layers of meaning" in the workshops with NATHEP participants and conference delegates and on our thinking as individual academic staff developers and as the NATHEP SC collective.

As an analytical approach, the four levels of layering in CLA above were used to make sense of the data (reflections) and interrogate implications of the data for "pedagogies in context". As a SC collective we acknowledge our various roles: NATHEP SC, workshop facilitators, academic staff developers, researchers, and authors of this paper in relation to the power influence within the CLA matrix (Inayatullah, 2004). As SC, we were personally influenced by the social forces of the pedagogies in context discourse and our efforts in disrupting the dominant assumptions of

Table 1: Description of CLA levels and the associated layers of the project 


\begin{tabular}{|c|c|}
\hline CLA Levels & This study: Layered analysis \\
\hline \multicolumn{2}{|c|}{ Level One } \\
\hline $\begin{array}{l}\text { Litany } \\
\text { Visible view of reality in which assumptions are } \\
\text { often not questioned }\end{array}$ & $\begin{array}{l}\text { NATHEP pedagogical approaches } \\
\text { Ontological: Pedagogy of Being and Becoming } \\
\text { Methodological: Pedagogy of Engagement } \\
\text { Epistemological: Pedagogy of Knowledge } \\
\text { Generation } \\
\text { Axiological: Pedagogy of Transformation and } \\
\text { Decolonisation } \\
\text { NATHEP activities with participants from February - } \\
\text { March } 2019\end{array}$ \\
\hline \multicolumn{2}{|c|}{ Level Two } \\
\hline $\begin{array}{l}\text { Social } \\
\text { Litany is explored, explained and questioned } \\
\text { Alternatives are explored }\end{array}$ & $\begin{array}{l}\text { NATHEP's pedagogical workshop encounters: } \\
\text { NATHEP Workshop in April } 2019 \text { with } \\
\text { NATHEP participants } \\
\text { HELTASA Conference Workshop in } \\
\text { November } 2019 \text { with conference delegates } \\
\text { SC Critical Dialogue: Conceptual disruption of } \\
\text { existing assumptions }\end{array}$ \\
\hline \multicolumn{2}{|c|}{ Level Three } \\
\hline $\begin{array}{l}\text { Worldview } \\
\text { A focus on ideological worldviews and } \\
\text { discursive assumptions }\end{array}$ & $\begin{array}{l}\text { Critical self-reflexive responses by SC on Pedagogical } \\
\text { Approaches } \\
\text { 2019- } 2020\end{array}$ \\
\hline \multicolumn{2}{|r|}{ Level Four } \\
\hline $\begin{array}{l}\text { Myth and Metaphor } \\
\text { The underlying story } \\
\text { Collective emotions and at times the } \\
\text { unconscious dimensions of the issue } \\
\text { Considers that there is more than one way of } \\
\text { knowing and different levels of reality }\end{array}$ & $\begin{array}{l}\text { Collective analysis: Critical group reflection by SC } \\
2020\end{array}$ \\
\hline
\end{tabular}

the NATHEP participants, conference delegates and ourselves within the two pedagogical encounters. Given the various roles we as the SC played, we also acknowledged the possible limitations of our own biases.

As suggested by CLA, the time, distance and critical reflection after the workshops enabled a deepened understanding and dialogic engagement with the unfolding layers as indicated in the table below representing both the methodological and analytical processes followed by the 
SC in conjunction with the CLA framework and NATHEP. The first column refers to the levels as determined by CLA and the second is the layers of the project and of how the SC engaged with findings and analysis within this study.

To enable and effect transformative changes, it is important to gain an understanding beyond the litany and social levels, in other words beyond the superficial. This includes the worldview and metaphoric levels. Each level will be presented below as findings and expanded on thereafter in the discussion and analysis, to enable the underlying story to unfold.

\section{Findings: Level One - Litany}

\section{Conceptual approaches to Pedagogies in the context of NATHEP}

Four domains are critical to both the success of NATHEP and its contribution to knowledge and practice. These include an explicit engagement with epistemological, ontological, methodological, and axiological domains of academic induction and ASD, as a field of scholarship and practice.

Using ontology as a lens, the SC explored how the coloniality of being manifests in how bodies are constructed, understood, and treated (Maldonado-Torres, 2007). For ASD, creating programmes for new academics, who are seen as 'fully constituted' with absolute powers to exercise their agency towards self-actualisation, is important now. This is linked with systemic issues of power and socio-cultural capital. The SC engaged a Pedagogy of Being and Becoming to explore what it means to recognise the full humanity of people who have a right to express their ontological density as thinking, feeling, and doing individuals in a collective, irrespective of race, gender, ability, religion, etc. A Pedagogy of Being and Becoming looked at how intersectionality manifests across structures to complicate the relational aspects of what it means to be a new academic in SA higher education today.

Using methodology as a lens, the SC explored the 'how to' of pedagogies for induction and how these can be accessed to maximise the involvement and participation of new academics (and their students) in their learning. A Pedagogy of Engagement was used to explore the spectrum of approaches used to create interactive learning contexts where all can find a sense of belonging and assert their voice.

Using epistemology as a lens, the SC interrogated the assumptions of epistemic traditions from the global North that displaced indigenous epistemic sites (Garuba, 2017) as credible and legitimate sources of knowledge. This erasure of indigenous knowledge, known as 'epistemicide' (de Sousa Santos, 2007), created the 'Other' at the periphery, whose knowledges were located at the margins and outskirts of mainstream knowledge production. In engaging with a Pedagogy for Knowledge Generation, opportunities have to be created in induction programmes, especially in the context of Africa, to re-center the knowledge of the Other, to re-assert marginalised voices and to legitimate their visibility and authenticity as knowledge producers. In NATHEP, a focus on pedagogies of knowledge generation drew attention to the importance of using appropriate pedagogical approaches to create conditions for academic developers and 
new academics to re-define their relation to knowledge, as active participants and authentic contributors rather than passive recipients.

Using axiology as a lens, the SC engaged with a social justice orientation to induction and academic staff development. Historically, social and epistemic injustice (Fricker, 2007) has been reproduced within the academic project through its assimilationist and compliance models. This cascades into other dimensions of social existence including sexuality, authority, subjectivity, politics, economy, spirituality, language, and race (Quijano, 2000). By drawing on the values and beliefs embedded in the transformation imperatives for $\mathrm{HE}$, the SC was able to ground the project in an orientation that is socially aware and socially just and in ways that espouse the relational ideals of ubuntu as an African philosophical approach to life. Linked to the transformation imperative, the SC explored how calls for decolonisation of curricula and a Pedagogy for Decolonisation / Transformation extended the transformation narrative to the realms of delinking (Mignolo, 2007) from traditional practices which reproduce the status quo.

Across these domains, several thematic threads have become important for knowledge building across the project that informs the curriculum for workshops and other events. These themes identified by the SC and NATHEP participants, included discussions on epistemic injustice, sociocultural conditioning, structural challenges, discourses on induction, and context, to name a few, that compete or comply with notions of academic identity and agency. Through rigorous thematic debate and discussion, NATHEP participants and conference delegates engaged with aspects that should be considered and contexualised if induction programmes aim to be responsive and relevant. Despite institutional differentiation and unevenly distributed resources across the sector, NATHEP participants devised contingencies to navigate through these to provide an improved induction intervention in their contexts by focusing on the knowing, being and doing of the new academic.

\section{Findings: Level Two - Social Pedagogical encounters}

A pedagogical encounter was the opportunity for the SC to put their approaches into practice and to explore, question and experience it 'on the ground' as with the Nathep participants and conference delegates. Each approach is undergirded by NATHEP's $\mathbf{C}^{\mathbf{3}} \mathbf{R}^{\mathbf{5}} \mathbf{i} \mathbf{T}$ ica $\mathbf{L}$ framework (Behari-Leak, et al., 2020,) which identifies imperatives for change namely Conceptual, Critical, Contextual, Responsive, Reflexive, Relational, Re-Centred, Relevant, Theorised, and Legitimate foci. Each approach builds on the 'pedagogical encounter' in ways that enable a teaching and learning relationship to emerge, providing the conditions for heightened awareness of context and a disruption of hegemonic assumptions and normalised practices. This is important to foreground and strengthen our positionality, position and purpose as $A D$ and academic staff developers within the context of a transforming $\mathrm{HE}$.

\section{Pedagogical encounter 1: NATHEP-April 2019 Workshop}


The workshop facilitated by the SC for NATHEP participants was based on pedagogies for developing critical agency when inducting new academics into the academy. The aim was for the Nathep participants to critically reflect on and explore the pedagogies that participants used in the design of their induction programmes. A range of pedagogical approaches aimed at engagement (methodological), knowledge generation (epistemological), being and becoming (ontological) and transformation and decolonisation (axiological) was shared by the SC. The SC as facilitators modelled each pedagogical approach, using various collaborative methods. The NATHEP university partners critiqued their institutional practices and generated new ideas for contextually relevant induction programmes aligned to their institutional realities.

\section{Pedagogical encounter 2: HELTASA Conference- 2019 November Workshop}

Drawing on insights and learnings from pedagogical encounter 1 , the SC facilitated a similar pedagogical encounter at the 2019 HELTASA conference through a workshop for national and international academic staff developers and academics. Drawing on practitioners' lived experiences, the conference workshop was based on interrogating dominant assumptions about the selection and use of pedagogies within various academic contexts. Disrupting traditional practices invited conference delegates to critically reflect on curriculum and pedagogical practices and to evaluate if they are adaptable to diverse ways of thinking, knowing and being. Interrogating our preconceived ideas and biases about the nature of learning and teaching formed an integral part of the reflection process. The selection of contextually relevant pedagogies is inextricably linked to who we are as practitioners and more importantly how comfortable we are with our own sense of being. Through active participation and an experiential approach, conference delegates considered how different pedagogies can enhance, disrupt, and challenge knowledge, being and doing in different contexts. Through modelling the various pedagogical approaches, a collaborative learning, teaching, and dialogic space was fostered amongst diverse conference delegates who were able to generate innovative, responsive, relevant, and transformative strategies aligned to the goals and imperatives of higher education.

\section{Conceptual Disruption: Pedagogies in context}

The HELTASA 2019 conference paid special attention to pedagogies in context, to enable critical appraisal of the AD field in South Africa. However, responses to the call could have misconstrued 'pedagogies in context' to simply mean pedagogies relevant for differentiated South African universities and their geographical locations rather than to re-imagine AD practices in the post-colonial university. The underlying assumption seems to be that university differentiation, in terms of university types and location, e.g. rural vs urban, warrants differentiated teaching practices (Boughey and McKenna, 2010). The danger in this view could be 'naturalising' the university and geography with the potential to obfuscate exploration of their 'structuring conditioning', which is an essential aspect if we are to re-imagine pedagogies that might enable transformation (Archer, 2000). At a practical level, a fertile ground is then created 
for extraversion ${ }^{1}$ and alterity $^{2}$ with the potential to constrain any possibility for endogeneity ${ }^{3}$ (Hountondji, 1990). It is our view that endogeneity involving the understanding of contextual specificities should serve as the basis to comprehend the inner workings of any social phenomenon.

Within the South African HE landscape, AD responses to contextual relevance have often conflated global asymmetrical epistemic relations of power with mere geographical location of scholars and in so doing, ignores the global north gaze that is often dominant and celebrated in AD scholarship in SA. We also trouble the claims about the existence of a 'wealth of research' produced in AD in SA. At a theoretical level we do acknowledge development of scholarship in the SA AD field (Boughey, 2010; Behari-Leak, 2017), but we cannot ignore contextual realities which continue to show stark 'presence of the past in the present' (Bhaskar, 2016). Celebration of theoretical developments in this field from a SA context, however, could be viewed as perplexing as we find it difficult to understand the proud proclamation of an abundance of valuable research in a context where universities continue to reproduce colonial epistemic relations of power (Ndlovu-Gatsheni, 2018). If we agree that the call for a decolonised HE was central to the student protests which engulfed SA HE in the 2015-2016 academic years, then the availability of a wealth of research (Boughey and Niven, 2012) should have provided a more effective curriculum and pedagogic response. A more responsible and relevant response to the student protest crisis should have rather been a realist question: What must the world be like given that black students and academics continue to experience alienation and marginalisation in SA HE?

At NATHEP, pedagogy is viewed beyond narrow classroom interactions and is therefore expansive. For us pedagogy entails all forms of education which seek to unmask oppression prevalent in social practices in HE so that changes can occur (Ramose, 2014). NATHEP is trying to expand the scope of $A D$ beyond an instrumentalist teaching and learning role to consider all struggles of those who continue to experience oppression in South African HE. These pedagogic acts should entail retroductive, transcendental arguments 'from premises familiar with from social practice' or from actors' own understandings of society (Collier, 1994: 167).

\footnotetext{
${ }^{1}$ Hountondji (1990) describes extraversion as an external oriented scholarship which seeks not only to meet theoretical needs of Western counterparts but also to answer the questions they pose. In critical realist terms extraversion can be viewed as a form of idealism and happens when the models developed to understand the world are conflated with the world and thereby imposed as universal theories across the world. In this context university types and their geographical location symbolise extraversion.

2 Mafeje (2011) views alterity as an external imposed categories/labeling which ignores specificity of contextual realities (South African universities are complex which cannot fit neatly to these external exposed categories).

3 Hountondji (1990) and Mafeje (2011) see endogeneity as an intellectual standpoint derived from rootedness in a particular context and thereby centring ontological discourse and experiences as a launchpad for authentic intellectual endeavour.
} 
It should be noted that it is retroductive arguments which lead to the development of pedagogic models often used to account for the conditions of the world that necessitate particular experiences to be possible. To re-imagine AD pedagogies in context requires that we consider the effects of coloniality in our HE system. We are reminded by Manathunga and Grant (2017) that higher education is implicated in local legacies of colonial violence towards indigenous peoples and their knowledges.

For historical structures like AD that were constituted through past forms of knowledge and beliefs about black students, it is important that practitioners constantly interrogate and shift these beliefs for transformation to be realised. Failure to do so might perpetuate the 'civilising' mission of AD in post-apartheid South Africa (Moulder, 1988). As Muller (1988) once cautioned, the civilising role $A D$ often plays, provides universities with an 'excuse not to change'.

\section{Findings: Level Three - Worldview \\ Critical self-reflection on Pedagogical Approaches}

The workshops focused on Pedagogies in Context by exploring four different approaches and modalities, to explore how pedagogy can be used as a mediating tool to achieve the intended aims. Each pedagogical approach with corresponding links to the epistemological, ontological, methodological, and axiological domains of NATHEP, was explored as a critical self - reflection by the four SC members who also facilitated the workshops. Each self - reflection will be unpacked next.

\section{Pedagogy of Being and Becoming (POBB)}

Early ideas about being emerged from Heidegger's fundamental ontology, through his opposition of an epistemologically oriented philosophy (Maldonado-Torres, 2007). Being was adopted by many others to motivate for an ontological turn for HE (Dall'Alba and Barnacle, 2007; Shawa, 2019). Decolonial scholars like Maldonado-Torres and Mignolo have challenged Heidegger's conceptualisation of Being (Maldonado-Torres, 2007). Heidegger's Being was notbeing and was indicative of one that is 'out there' thus negating their lived experiences and the colonial side of being (Maldonado-Torres, 2007). As argued by Maldonado-Torres (2007) it was the colonial matrix of power (Quijano, 2000) that led to the coloniality of being which devalues human beings in terms of race, class, gender, and sexuality. Emanating from Descartes 'Cogito, ergo sum,' 'I think, therefore I am' - I think, others don't (Maldonado-Torres, 2007), was a dualist approach that marginalised certain races as inferior and lacking rationality (Quijano, 2000).

Drawing on Du Bois's decolonial attitude, Maldonado-Torres (2007: 262) advocates for a 'decolonial turn that will make the invisible visible and should include the critical reflections of the "invisible" people themselves'. This resonates with Mbembe's (2015) provocation for creating a set of 'mental dispositions' and enabling 'pedagogies of presence'. He avers that '[b]lack students and staff have to invent a set of creative practices that ultimately make it impossible for official structures to ignore them and not recognise them, to pretend that they are not there; to 
pretend that they do not see them; or to pretend that their voice does not count' (Mbembe, 2015: 6).

The aforementioned conceptions of being, power and coloniality of being bears semblance with SA HE, deeply embedded in a history of subjugation and marginalisation, silencing not only the voices of people but also their being and further becoming. This history was evidenced in the 2015 student protests that attested to the misrecognition of who our students are (Fataar, 2019), their sense of alienation, and not aligned to the materials, colonial structures and ensuing cultures that permeate their being and becoming in $\mathrm{HE}$. As the SC we realised that as practitioners we may have internalised the coloniality of being at our universities in ways that lead us to doubt our authentic selves and our ability to relate authentically to staff and students.

With its transformative and decolonial underpinnings, NATHEP recognises and acknowledges the self and who the self becomes through the process of engagement with pedagogical encounters. By focusing on a PoBB, it is important to evoke the whole person into the pedagogical encounter. The teacher and student should be in a relational interaction that recognises positionality, lived experiences and dispositions. Being and becoming are not mutually exclusive but entangled and occur intra-actionally (Barad, 2007).

NATHEP recognised and acknowledged the influence of personal and institutional histories in shaping and conditioning particular ways of knowing, being, doing and becoming. In The Courage to Teach Parker Palmer (2007) contends that we teach who are. PoBB provides opportunities for teachers and students to draw on their lived experiences and interrogate who they are, how they have been conditioned by the socio-cultural and historical context and how they in turn shape context. Part of this self-knowledge should encompass a critical understanding of our often-unconscious assumptions that drive and shape our actions and behaviours. These transformative learning (Mezirow, 2000) encounters can be facilitated through a PoBB to enable an understanding of how context privileges and legitimates some and not others while recognising the complexities in enculturating our own students in uncritical ways (Taylor, et al., 2012).

\section{Pedagogy of Engagement (POE)}

What it means to 'engage' pedagogically is relative to who is being engaged and who is facilitating the engagement. Engagement then is at the behest of the person in power in that space, namely the teacher. Educators use a variety of social constructivist strategies and interventions to engage their students (Edgerton, 2001), namely active and cooperative learning, learning communities, service learning, cooperative education, inquiry and problem-based learning, and team projects (Smith, et al., 2005). These pedagogical tools are used differently in disciplinary contexts to achieve different objectives.

In NATHEP, the SC have found that until 'engagement' is critical, conscious, and socially aware, it can do very little to disrupt the power relations in pedagogical spaces based on race, class, gender, ethnicity, language and age. Power imbalances often keep people trapped in hierarchies of power and servitude, socialising them into reproducing the status quo (Freire, 1996; 
hooks, 1994). Historically, through a pedagogy of (dis) engagement, or what Freire (1996) calls a 'banking model', people have learnt how to be complicit, docile, conformist and spectators in their own subjugation and oppression, unable to make independent decisions or exercise their agency to transcend the limitations of their material conditions. When students learn 'about' content (absorbed, memorised, and recalled) rather than 'through' content (contextualised), they become passive recipients of knowledge; counterproductive to the active and critical students HE has an obligation to groom.

In her book Teaching to Transgress, hooks remind us that our work as teachers is to engage by sharing in the intellectual and spiritual growth of our students and by teaching in ways that transgress the boundaries that confine each pupil to a rote, assembly-line approach to learning (hooks, 1994). To embrace a pedagogy of engagement, we need to engage at the level of the intellect but also at the level of affect and emotion including social and cultural levels. A decontextualised approach to teaching and learning results in dis-engagement with the world, knowledge, and each other. Students could then understand the world as static and unchangeable, one in which they are supposed to fit into. With no real and critical engagement, certain truths masquerade as universal and 'normal' for all, reducing and essentialising the specific experiences of individuals to anomalies of the hegemonic narratives that command attention, scrutiny and value (Dastile and Ndlovu-Gatsheni, 2013).

In NATHEP, the SC recognised that as academic staff developers, we have also been socialised into particular engagement models which we may have uncritically mimicked and reproduced without considering context or purpose. To resist falling into the trap of passivity and conformity, Freire (1996) advocated for teachers and students to develop a critical consciousness, conscientisation, or conscientização, for teachers to enact an education that is the "practice of freedom' (hooks, 1994). The term "critical consciousness" based on Fanon's coinage in Black Skins, White Masks (1991), calls on people to be awake to their oppression and actively work to resist it. Student activists have raised our awareness about the dangers of colonial pedagogies that by design, result in students feeling alienated, marginalised, and invisible. Where the classroom ethos favours re-enforcement of the dominant culture through language, texts, discourse, examples, and artefacts that reinforce a Eurocentric bias, students at universities in Africa are unable to assimilate and be successful while their sense of self and positionality are negated and minimised. Amplifying Freire's goals, Kincheloe (1999) formulated 'postformal' critical consciousness, linking questions of power and social justice by engaging with questions of purpose, issues of human dignity, freedom, authority, reconceptualised notions of reason, intellectual quality, and social responsibility.

NATHEP asserts a decolonial pedagogy of engagement where the SC and participants can develop a critical consciousness of our historical and social contexts and how these have constrained our embodied and contextualised learning, indigenous knowledge practices, representation, and inclusion. Through exclusions, coloniality is a mechanism for people to psychologically split off from who they really are. A decolonial PoE involves dialogue among interlocutors who ask critical questions about the 'voice' of the subaltern (Spivak, 1988), how 
people are represented and spoken for, and whether people can exercise their own voice without fear of punishment.

A PoE, in the SC's view, is a form of teaching and learning that invites students and the teacher to be fully present and socially aware; and to participate with their full beings by bringing their positionality, identity and ontologies into the space, without fear of ridicule or embarrassment. A PoE works actively against alienation, silencing, marginalising, or making invisible those on the periphery and margins. A PoE needs to create conditions to amplify the philosophy of ubuntu (Ramose, 2019), to co-create and engage a relational pedagogy that serves all.

\section{Pedagogy of Knowledge Generation (PoKG)}

A pedagogy of knowledge generation (PoKG) should seek to enable critical engagement with: theories of knowledge generation being socio-historical, political and cultural processes of meaning making (Collins, 2000); social and racialised forces shaping knowledge production and reproduction (Wyse, 2015); a coloniality of knowledge reflexive of the political - economic coloniality of power and its denial of other forms of knowledge (de Sousa Santos, 2007); a globalised localism of Eurocentric and ethnocentric knowledge which is often normalised and legitimised as the only path of valid knowledge production (Stanfield, 2011); a mono cultural Eurocentric knowledge that tends to deny the validity of racially Othered knowers and knowledges while promoting an alienating culture (Smith, 2012). A PoKG must seek to understand epistemological access in relation to personal and contextual relevance while acknowledging the three essential elements of epistemology: the knower, the known and the process of knowing (Sprague, 2016). Collectively this triad allows for an analysis of the ways in which power relations shape who is believed and why (Collins, 2000).

As academic staff developers and academics within an African context, we should be interrogating our role as facilitators of knowledge generation by asking deep questions about whose knowledge is privileged, whose interests are served, which kinds of knowledges are prioritised at the expense of others and what structures and conditions exist for the advancement of these knowledges. The pedagogy itself must disrupt essentialised and normative understandings of the production and purpose of knowledge including the role of knowledge as part of the social and academic project.

Our views about knowledge and it's changing nature (Gilbert, 2005) and often copying the methods of our teachers shapes the selection of pedagogy and tools validating what we value as powerful knowledge and who is able to generate knowledge. Instead of new academics assimilating the "tried and tested" methods used previously, NATHEP's POKG encouraged the disruption of dominant epistemological assumptions to enable a theorised consideration of pedagogical approaches for contextualised knowledge generation. Induction needs to draw attention to disciplinary boundaries, knowledge and gatekeepers who legitimise the validity of knowledge through ideas and assumptions considered the truth (Collins, 2007). These boundaries and gatekeeping reflect the structured power relations that reproduce hegemonic, elite 
knowledge that perpetuate societal power relations (Freire, 1996). As cautioned by Bourdieu, we should ensure that our disciplinary aims for knowledge generation do not invisibly produce socialised persons that embody the hegemonic power systems and reproduce structured power relations often taken for granted while also invisible (Collins, 2007).

Gilbert (2005) indicates that new knowledge is a process not produced in the minds of people but in the interactions between people. In knowledge generation pedagogies, as opposed to knowledge reproduction pedagogies, orientations and dispositions towards diverse forms of knowledge are important. Entwistle (2000) encourages academics to work with deeper approaches to teaching and learning through activities that focus on analytical and critical thinking, problem solving and dialogical discussion while assessments should be based on analysis, synthesis, comparison, and evaluation.

PoKG requires a strong teacher presence where conversations, debate, discussions, vulnerabilities and thinking about the world in alternative and new ways are enabled amongst all, including the teacher. A collaborative dialogic learning space that fosters analytical thinking and reflective judgement can be encouraged (Laurillard, 2002) through a teacher who is able to facilitate disrupting, challenging, questioning lived contexts through innovative and authentic knowledge application and integration.

As a space for knowledge disruption and knowledge generation, NATHEP enabled the SC and participants to consider how education has been used as a tool to mis-educate, colonise minds (Fanon, 1965) and to further question the coloniser's language demands as spiritual subjugation (Ngugi, 1986). Distorting and mis-representing the history of the colonised as western formal education shapes the way we are able to see and know or don't see or don't know our social world and social reality (Wyse, 2015). As the SC, NATHEP participants and conference delegates, we were able to discern that while education and knowledge can be used as a tool to oppress, dialectically it can also be used for liberation (Wyse, 2015) and with nuanced facilitation of knowledge generation pedagogies an imagination for alternative possibilities for diverse contexts can be fostered.

\section{Pedagogy of Transformation and Decolonisation (POTD)}

Decolonial pedagogies move from the premise that context matters in education. Here context refers to the legacy of colonial education which continues to shape ways of thinking, acting and being the victims of colonialism. This challenges academics to constantly examine ideological bias inherent in colonial education which renders education incapable of facilitating liberation and shared democracy (de Sousa Santos, 2007). At the centre of decolonial pedagogies is a concern with ways in which the colonial education system is structured so as to reproduce unequal relations of power and perpetual subjection of the colonial subject. This subjection creates a kind of African subjectivity that is enclaved with the colonial stereotype of being characterised by lack and deficit (Ndlovu-Gatsheni, 2018). Decolonial pedagogies therefore call for epistemic justice to enable the oppressed to re-imagine a world beyond the present (Mills, 2017; Mafeje, 2000). 
To achieve epistemic justice requires 'centering of African culture' at the heart of the academy and development (Nyoka, 2017). Decolonial pedagogies challenge academics to reimagine theoretical frameworks able to account for our lived experiences (as African people) and our relationality with other learners rooted in our cultures, histories, and heritage (Dei, 2012). Mafeje (2011) calls this endogeneity and foregrounds its centrality for the authentic African scholarship. This speaks to a scholarship that is grounded in African ontological discourses and experiences.

Endogeneity and rootedness are presented as the best ways to counter what Hountondji (1990) referred to as extraversion. Extraversion challenges Eurocentric assumptions about the existence of universal knowledge and theories used to explain social phenomena across space and time. Through extraversion, we are being challenged to seriously consider specificities of context by avoiding pedagogies imposed by Eurocentric models. It should be noted that this doesn't mean complete rejection of theoretical tools from the global North but rather calls for careful appropriation to allow the empirical world to speak for itself. For Alatas, uncritical application of theories from the West is a reflection of what he calls 'captive mind' (2018: 8) which enables application of the western social sciences without appropriate adaptation.

Decolonial pedagogies enable the oppressed to strengthen their calls for corrective justice as a counter-hegemonic mechanism predicated on Rawlsian theory of distributive justice (as cited in Mills 2017). Decolonial pedagogies challenge distributive justice as a form of extraverted theory (ideal theory), not able to correct the wrongs of the past in non-ideal (ill-ordered) societies. Decolonial pedagogies emphasise the importance of lived experiences of the colonised as a starting point in dealing with injustices hence the calls for corrective or rectification justice (Mills, 2017).

Decolonial pedagogies are realist pedagogies. They require that we ask this realist question: - what must the world be like given that black students (and academics) continue to experience alienation and marginalisation in South African HE?

\section{Analysis at Level Four: Myth and Metaphor SC collective analysis: disrupting the myths}

Focusing on level three (worldview) of the CLA, the authors looked across the self- reflexive responses to select the most poignant underlying mechanisms that drove their reflection across the pedagogical approaches. This level of the Myth and Metaphor of the CLA prompted the SC to analyse, at a deeper level, why pedagogical encounters happen the way they do. Through this collective analysis, the SC generated the metaphor of the portal for flexibility and agility in envisioning alternative futures for any or all contexts.

The key thematic threads that follow demonstrate how pedagogical encounters or myths that have been historically constructed were discussed in relation to portability. 


\section{Separateness and detachment}

Across all four pedagogies engaged with at NATHEP, the underlying cultural mechanism influencing how discrete pedagogies have been traditionally and historically conceived and enacted in hegemonic spaces is that of separateness and detachment, in other words, a pedagogy of (dis) engagement. Teaching and learning engagements have occurred culturally and socially in pedagogical ways that (un)consciously distance and alienate by highlighting the fissures and friction in our socio-material HE spaces. These occur through markers of difference that accentuate privilege and power which serve to entrench a process of disembodied and disassociated engagement, severed from the collective agency needed for transformation. Pedagogies are often uncritically used to reify 'difference', which in the post-1994 era of rainbowism and multiculturalism has been celebrated as a romantic and exotic commodity. This form of engagement masks the fault lines of deficit and profit through which linguistic disparity (Ngugi, 1986; Achebe, 1958), epistemic injustice and epistemicide (Mignolo, 2007), knowledge reproduction, ontological paucity (Fanon, 1991; Grosfoguel, 2011), disciplinary decadence (Gordon, 2013), and the coloniality of being (Torres, 2007; Biko, 1978) play out in our HE spaces. We are often unaware of how our positionality and identity are inserted in our contexts in normalised ways, are superimposed in an already contested landscape where who we are is intimately linked with what we know, what we do and how we make sense of our worlds. A pedagogy of engagement to be enacted in socially and critically conscious ways requires an awareness and presence of purpose conscious of the interplay between who is in our classrooms, what knowledge they bring in and how these are legitimated (or not). It is important to create conditions for a pedagogy that goes beyond performative activities that might appear to be engaging, but which actually serve to negate, alienate and marginalise the very students we seek to support.

\section{Epistemic injustice}

Epistemic injustice can be experienced as an invisible manifestation of power (Mignolo, 2007) and a silent underlying cultural mechanism implicit across all four pedagogical approaches. The conceptions of epistemic access (Morrow, 2015) and taken for granted assumptions shape the enactment of all four pedagogical approaches. When pedagogies adopt surface approaches, they inadvertently perpetuate epistemic violence, language subjugation (Ngugi, 1986) and assimilation practices. An overemphasis on content offers little thought to knowledge integration for praxis and ontological access. A narrow pedagogical approach to epistemic access disregards the knower or the being and the process of knowing and becoming. Pedagogies that do not embrace diverse forms of knowledge particularly knowledge of self, community, and experience, can invoke silences, non - participation, disengagement, feelings of unhomeliness (Bhabha, 1994), marginalisation and alienation.

Epistemic justice within NATHEP's pedagogies called for a re-centering of knowledge in an African context with an iterative world view. A context where knowledge is re(produced) through concrete understanding of the natural and social environments and a lived reality that embraces 
social responsibility (Abdi and Cleghorn, 2005). A PoKG requires an epistemological shift that represents a world of plural knowledge forms and engaged knowers who are critical, transformative and decolonial African centred beings.

\section{Social (in)justice}

What can be deduced from all four SC reflective pieces, that formed the data, is a concern over ways in which pedagogies continue to be complicit in rather than condemnatory of the subjugation of black people in the post-colonial HE space. All four pedagogies reflected on, paint a picture of ways in which practices facilitate the reproduction of a system that deprives the oppressed of agency to change material conditions. While social justice is a dominant discourse in SA HE, it seems as if pedagogies remain oriented towards an 'ideal world' providing theories for a perfectly just society (Mills, 2017). This form of ideal creates a situation where pedagogies become empty slogans with a morally charging discourse while abstracting away from social oppression. Such pedagogies not only fail to make visible the structures of oppression but enable transmutation of white domination into white hegemony (Madlingozi, 2018).

According to Mafeje's (1997) analogy of African intellectuals, these 4 pedagogies could be viewed as a reflection of both 'complacent' and 'shanghaied' academics. The former refers to passive intellectuals who cannot challenge the status quo, while the latter are engaged intellectuals who lack rootedness (endogeneity), seduced by Western theoretical frameworks and often unable to engage with contextual realities. These pedagogies could then enable the system to reproduce itself ideologically while perpetuating social injustices.

\section{Technocratic rationality and instrumentalism}

Technocratic logics and instrumentalist pedagogies view teaching and learning through the perspective of performativity where a neoliberal and managerialist canon pervades focusing on the development of technical skills. Such a discourse of performance and measurement creates alienation between the act of teaching and the purpose of teaching and the person doing the teaching. Performative pedagogies foreground management, competencies, evaluation, teaching techniques, classroom discipline, and control. What is neglected is the lived realities of the people in the classroom and the existential component of the being-who-teaches-andlearns and who they become through the encounter. Perpetual subjugation and denial of one's identity can render one complicit in their own oppression and situatedness (Freire, 1976; Spivak, 2016) leading to cognitive damage (Amin, et al., 2016), that is to accept and inhabit impositions antithetical to the sense of self.

Amin, et al. (2016) argue further that such cognitive damage is inflicted upon the oppressed, by those responsible for such oppression and who seek to maintain the status quo. A detached pedagogical approach espouses normative worldviews associated with globalisation, vocationalism and pedagogies that serve to legitimise dominant knowledge systems and 'epistemologies of alterity' (Mafeje, 1997). Epistemological access in this case is privileged over the recognition and inclusion of the ontological being. 
Countering the hegemony of technocratic and instrumentalist logics calls for educating the whole human being: personal, social, educational, and spiritual.

\section{Metaphorical insights}

As discussed earlier, the metaphor of the portal emerged from the analysis to represent the flexibility and agility of pedagogies in context. What also emerged from the analysis is the notion that agile and portable pedagogies can be resilient irrespective of the context. The SC's dialogic engagements have conjured up the imagery of teleporting to a distant future and the teleporting of pedagogies to diverse contexts. The timeous significance of this notion in the current COVID19 crisis, that has precipitated the pivot to a fully online mode, cautions against the fallacy that pedagogies can be transported uncritically into diverse contexts and used in technocratic ways.

The portal enables pedagogies that are contingent to and reliant on context, especially in the global South where a groundedness and centredness in what it means to be African, is critical. $\mathrm{HE}$ needs to re-articulate its belief and commitment to re-imagined pedagogies that demonstrate togetherness and relatedness, echoing the concept of Ubuntu in African philosophy. The HE sector should work in humanity's best interests to transform pedagogies in context so that we can usher in a world that aspires to human flourishing for all.

\section{Conclusion}

Cultivating and enhancing human agency in order to achieve a better world means that academic developers need to think about the development and enhancement of pedagogies that will widen academic and student capabilities to enjoy freedom and make the universe a better place. The SC views epistemic justice as a prerequisite for pedagogies in context. These enable a shared democracy and serve as an important mechanism to dismantle and renegotiate the power relations that structure human society mainly through knowledge reproduction. Epistemic justice requires an ability to draw on pluriversal knowledges in an open society.

Relationality is consonant with open societies. For Mafeje (1994) relationality entails endogeneity and being grounded in African ontological being as authentic African interlocutors. Achieving this relationality requires decolonial pedagogies to foreground pedagogies of engagement and being and becoming. Decolonial pedagogies and decolonial scholars are driven by the vision of new humanness (Ubuntu) - a world beyond the present. This requires a suite of contextualised pedagogical encounters, collective agency, and transformative praxis to establish our rootedness in who we are as African people, our culture and knowledges in relation to other people in the world and their cultures and knowledges.

To embrace a form of collective agency and given the interrelated nature of the university and $\mathrm{HE}$ as a structural and socio-cultural system, it is hoped that with alternative theorisation and creation of conducive conditions for critical pedagogical agency, academic staff developers and academics are able to create pedagogically contextualised, sensitised, responsive, and informed curricula for their respective programmes. 


\section{Author Biographies}

Rieta Ganas is an Educational Developer and Higher Education Lecturer in the Centre for Learning, Teaching and Development at the University of the Witwatersrand. Rieta's coordination, conceptualisation, and facilitation within academic staff development work at Wits promotes collaborative academic scholarship through the exploration of self in relation to the academic role, teaching and learning, and curriculum development and design practices within Higher Education. Her scholarship interests include the enhancing of agency through self exploration and professional learning opportunities.

Kasturi Behari-Leak (Associate Professor) is the Deputy Dean: Teaching and Learning in the Centre for Higher Education Development at UCT and Interim Director of the Academic Staff and Professional Development Unit. She teaches on formal and informal professional development courses and her work explores lecturers' critical agency in a contested global South context. She was co-chair of the Curriculum Change Working Group at UCT. She is President of the HELTASA and convenes its PhD Programme. She is President of the International Consortium of Educational Development. She leads a national collaborative project on academic staff development and serves on the research advisory committee of the World Universities Network.

Nalini Chitanand has practiced in academic development for more than two decades. She leads a number of staff development programmes within the university and participates in national and international collaborative projects. Nalini's passion is fostering the scholarship of teaching and learning. She is currently co-editing a book on Academic Staff Development.

Siya Sabata is a lecturer in Curriculum Development and Renewal at the Cape Peninsula University of Technology (CPUT). He is also part of Fundani: Centre for Higher Education and Development. Siya is the is the co-founder and the leader of CPUT curriculum decolonial group. He is also teaching in a Post Graduate Diploma in Higher Education (PGDiP), a collaborative programme in the Western Cape Province. Siya is a critical realist scholar inspired by philosophy of the late Roy Bhaskar and works in a field of academic staff development (AD).

\section{References}

Abdi, A. \& Cleghorn, A. (eds.) 2005. Issues in African Education: Sociological perspectives. New York: Palgrave Macmillan.

Achebe, C. 1958. Things Fall Apart. Essex, England: William Heinemann.

Alatas, H. 2018. Intellectuals in Developing Societies. London: CASS Routledge.

Amin, N., Samuel, M. A. \& Dhunpath, R. 2016. Undoing cognitive damage. In Samuel, M.A., Dhunpath, R. \& Amin, N. (eds.) Disrupting Higher Education Curriculum. Rotterdam: Brill Sense, 1-16.

Archer, M.S. \& Archer, M.S. 2000. Being Human: The Problem of Agency. Cambridge: Cambridge University Press. 
Barad, K. 2007. Meeting the Universe Halfway: Quantum Physics and the Entanglement of Matter and Meaning. Durham, London: Duke university Press.

Behari-Leak, K. 2017. New academics, new higher education contexts: A critical perspective on professional development. Teaching in Higher Education, 22(5): 485-500.

Behari-Leak, K., Ganas, G. Sabata, S., Chitanand, N. \& Toni, N. 2020. A Deep Dive into Curriculum Complexities in the Time of COVID-19. In Ramrathan, L., Ndimande-Hlongwa, N., Mkhize, N. \& Smit, J.A. (eds.) Re-thinking the Humanities Curriculum in the Time of COVID-19. Durban: CSSALL Publishers, i-xv; 1-192.

Bhabha, H.K. 1994. Frontlines/Borderposts. displacements: Cultural identites in question. Indiana UP, Bloomington, 199-211.

Bhaskar, R. 2010. Reclaiming Reality: A Critical Introduction to Contemporary Philosophy. New York: Verso Taylor \& Francis.

Bhaskar, R. (2016). Enlightened common sense: The philosophy of critical realism. London, England: Routledge.

Bhaskar, R. (ed.) 1990. Harré and his Critics: Essays in honour of Rom Harré with his Commentary on them. B. Blackwell.

Biko, S. 1978. I write what / like. London, England: Bowerdean Press.

Boughey, C. \& McKenna, S. 2010. A Meta-analysis of five Comprehensive Universities. Pretoria. Council on Higher Education.

Boughey, C. \& Niven, P. 2012. The emergence of research in the South African academic development movement. Higher Education Research \& Development, 31(5): 641-653.

Boughey, C. 2010. Academic development for improved efficiency in the higher education and training system in South Africa. Development Bank of Southern Africa, 1-31.

Collier, A. 1994. Critical Realism: An Introduction to Roy Bhaskar's Philosophy. London: Verso.

Collins, P.H. 2000. Gender, black feminism, and black political economy. The Annals of the American Academy of Political and Social Science, 568(1): 41-53.

Collins, P.H. 2007. Going public. Public sociology. Fifteen eminent sociologists debate politics and the profession in the twenty-first century, 101-113.

Dall'Alba, G. \& Barnacle, R. 2007. An ontological turn for higher education. Studies in Higher Education, 32(6): 679-691.

Dastile, N. P. \& Ndlovu-Gatsheni, S. 2013. Power, knowledge and being: Decolonial combative discourse as a survival kit for Pan-Africanists in the 21st century. Alternation, 20(1): 105134.

de Sousa Santos, B. 2007. Another Knowledge is Possible. Beyond Northern Epistemologies. London, England: Verso.

de Sousa Santos, B. 2018. The End of the Cognitive Empire: The Coming of Age of Epistemologies of the South. Duke University Press.

Dei, G. 2012. Indigenous anti-colonial knowledge as 'heritage knowledge' for promoting Black/African education in diasporic contexts. Decolonization: Indigeneity, Education \& Society, 1(1): 102-119. 
Edgerton, R. 2001. Education White Paper. http://www. pewundergradforum.org/wp1.html.

Entwistle, N. 2000. Approaches to studying and levels of understanding: The influences of teaching and assessment. Higher Education, 15: 156-218.

Fanon, F. 1965. A Dying Colonialism, trans. H. Chevalier. New York, NY: Grove.

Fanon, F. 1991. Black Skin, White Masks, trans. C.L. Markmann. New York, NY: Grove.

Fataar, A. 2019. Academic conversation: From the shadows to the university's epistemic centre engaging the (mis)recognition struggles of students at the post-apartheid university. Southern African Review of Education, 25(2): 22-33.

Freire, P. 1996. Pedagogy of the Oppressed. London, England: Penguin.

Fricker, M. 2007. Epistemic Injustice: Power and the Ethics of Knowing. New York. Oxford University Press.

Garuba, H. 2017. Teacherly texts: Imagining futures in Nuruddin Farah's Past Imperfect Trilogy. Boundary 2, 44(2): 15-30.

Gilbert, J. 2005. Catching the knowledge wave? The knowledge society and the future of public education in New Zealand. Education Policy Directions in Aotearoa/New Zealand, 53-70.

Grosfoguel, R. 2011. Decolonizing post-colonial studies and paradigms of political-economy: Transmodernity, decolonial thinking, and global coloniality. Transmodernity: Journal of Peripheral Cultural Production of the Luso-Hispanic World, 1(1): 1-37.

Haigh, M. 2016. Fostering deeper critical inquiry with Causal Layered Analysis. Journal of Geography in Higher Education, 40(2): 164-181.

hooks, b. 1994. Teaching to Transgress: Education as the Practice of Freedom. New York, NY: Routledge.

Hountondji, P. 1990. Scientific dependence in Africa today. Research in African Literatures, 21(3): $5-15$.

Inayatullah, S. 2004. Causal layered analysis: Theory, historical context, and case studies. In Inayatullah, S. (ed.) The Causal Layered Analysis Reader: Theory and Case Studies of an Integrative and Transformative Methodology. Tappei, Taiwan: Tamkang University Press, $1-52$

Kincheloe, J.L. 1999. The struggle to define and reinvent whiteness: A pedagogical analysis. College Literature, 26(3): 162-194.

Laurillard, D. 2002. Rethinking teaching for the knowledge society. EDUCAUSE review, 37(1): 16 25.

Madlingozi, T. 2018. Mayibuye iAfrika?: Disjunctive Inclusions and Black Strivings for Constitution and Belonging in 'South Africa'. Unpublished PhD diss., University of London.

Mafeje, A. 1994. Beyond academic freedom: The struggle for authenticity in African social science discourse. Academic Freedom in Africa, 59-72.

Mafeje, A. 1997. Ethnicity and intra-class conflict in Africa. Unpublished mimeograph.

Mafeje, A. 2011. Africanity: A combative ontology. In Devisch, R. \& Nyamnjoh, F.B. (eds.) The Postcolonial Turn: Re-Imagining Anthropology and Africa. Cameroon: LANGAA RPCIG, 3144. 
Maldonado-Torres, N. 2007. On the coloniality of being: Contributions to the development of a concept. Cultural Studies, 21(2-3): 240-270.

Manathunga, C. \& Grant, B. 2017. Southern theories and higher education. Higher Education Research and Development, 36(1): 1-3.

Mbembe, A. 2015. Decolonizing knowledge and the question of the archive. Public lecture, Johannesburg, Wits Institute for Social and Economic Research (WISER).

Mezirow, J. 2000. Learning as Transformation: Critical Perspectives on a Theory in Progress. The Jossey-Bass Higher and Adult Education Series. San Francisco, CA: Jossey-Bass Publishers.

Mignolo, W.D. 2007. Delinking: The rhetoric of modernity, the logic of coloniality and the grammar of de-coloniality. Cultural Studies, 21(2/3): 449-514.

Mills, C. 2017. Black Rights/White Wrongs: The Critique of Racial Liberalism. New York, NY: Oxford University Press.

Morrow, W. 2015. Bounds of Democracy: Epistemological Access in Higher Education. Cape Town: HSRC Press.

Moulder, J. 1988. 'Africanising' our universities: Some ideas for a debate. Theoria: A Journal of Social and Political Theory, 1-15.

Muller, J. 1988. Coming in from the margins: Options for academic support in a pluralist university. Academic Support Conference. University of Cape Town.

Ndlovu-Gatsheni, S.J. 2018. Epistemic Freedom in Africa: Deprovincialization and Decolonization. London, England: Routledge.

Ngugi wa Thiong'o. 1986. Decolonizing the Mind: The Politics of Language in African literature. Nairobi, Kenya: Heinemann Education.

Nyoka, B. 2017. Archie Mafeje: An intellectual biography. Unpublished PhD diss., University of South Africa.

Palmer, P.J. 2007. The Courage to Teach: Exploring the Inner Landscape of a Teacher's Life. San Francisco, California: Jossey-Bass.

Quijano, A. 2000. Coloniality of power and Eurocentrism in Latin America. International Sociology, 15(2): 215-232.

Ramose, M. 2014. Ubuntu: Affirming and Right and seeking Remedies in South Africa. In Praeg, L. \& Magadla, S. (eds.) Ubuntu: Curating the Archive. Scottsville, South Africa: University of KwaZulu-Natal Press, 121-139.

Ramose, M. 2019. A philosophical investigation into the conceptual history of decolonisation in Africa. Presentation at the Unisa Decoloniality Summer School, Pretoria, South Africa. January 2019.

Ranciere, J. 1999. Dis-Agreement. Politics and Philosophy. London, England: University of Minnesota Press.

Shawa, L.B. 2019. Beyond epistemology: Ontological transformation in South African universities. In Scott, C.L. \& Ivala, E.N. (eds.) Transformation of Higher Education Institutions in PostApartheid South Africa. New York: Routledge, 109-120. 
Smith, K.A., Sheppard, S.D., Johnson, D.W., \& Johnson, R.T. 2005. Pedagogies of engagement: Classroom-based practices. Journal of Engineering Education, 94(1): 87-101.

Smith, L. 2012. Discourses of heritage: implications for archaeological community practice. Nuevo Mundo Nuevos Mundos. https://doi.org/10.4000/nuevomundo.64148

Spivak, G.C. 1988. Can the subaltern speak? In Nelson, C. \& Grossberg, L. (eds.) Marxism and Interpretation of Culture. Basingstoke, country: Macmillan Education, 271-313.

Spivak, G. 2016. Humanities, democracy and the politics of knowledge in higher education. In Samuel, M.A., Dhunpath, R. \& Amin, N. (eds.) Disrupting Higher Education Curriculum: Undoing Cognitive Damage. Rotterdam: Sense Publishers, 17-30.

Sprague, J. 2016. Feminist Methodologies for Critical Researchers: Bridging Differences. Walnut Creek, CA: Altamira Press.

Stanfield, John H. II. 2011. Historical Foundations of Black Reflective Sociology. Walnut Creek, CA: Left Coast Press

Taylor, P.C., Taylor, E. \& Luitel, B.C. 2012. Multi-paradigmatic transformative research as/for teacher education: An integral perspective. In Tobin, K.G., Fraser. B.J. \& McRobbie, C. (eds.) Second International Handbook of Science Education. Dordrecht, The Netherlands: Springer, 373-387.

Wyse, J.P. 2015. Black Sociology: The Sociology of Knowledge, Racialized Power Relations of Knowledge and Humanistic Liberation. Burlington, VT: Ashgate Publishing Company. 